\title{
Introduction: Tight Junctions and Secretory Activation in the Mammary Gland
}

\author{
Margaret C. Neville
}

Published online: 4 August 2009

(C) Springer Science + Business Media, LLC 2009

Studies as early as 1915 showed that the concentration of sodium and chloride in human milk declined rapidly from birth to about 5 days post-partum (reviewed in [2]). Figure 1 shows these composition changes derived from a more recent study [1]. In the cow similar observations were made dating back to the 1930s (reviewed in [3]). Following earlier hypotheses, Barry and Rowland attributed these observations to variable degrees of mixing of extracellular fluid with the secretion product of the alveolar cells. Linzell and Peaker studied the changes in milk composition in detail as part of their studies on the mechanisms by which the ionic composition of milk is maintained in the dairy goat [4]. In addition, they utilized fluxes of isotopes from the blood stream into the udder or visa versa, and were able to show that the epithelium is impermeable to disaccharides in the lactating animal. In their article reprinted here [5], these authors describe similar experiments in pregnant goats showing that changes in sodium, chloride, and lactose parallel the changes in human milk shown in Fig. 1 and that during pregnancy the epithelium is permeable to both lactose and sucrose. They ascribe these findings to a change in the permeability of the tight junctions at the onset of lactation.

At the same time as these functional experiments were being carried out at Babraham, Cambridge, Dorothy Pitelka and her colleagues at Berkeley were exploring the cell contacts in the luminal epithelium of the mammary gland at various stages of development [6]. They showed four varieties of contacts: tight (occludens) junctions, intermediate (adherens) junctions, desmosomes, and gap junctions. The first three were confined to epithelial layers and serve both to stabilize their structure and to provide a barrier, which may be selective, between the

M. C. Neville $(\triangle)$

UCDenver School of Medicine,

Aurora, CO, USA

e-mail: peggy.neville@ucdenver.edu luminal and basolateral fluid compartments. Gap junctions formed between epithelial cells but also, in the mammary gland, between epithelial and myoepithelial cells. This classic article, reprinted here, continues to inform our understanding of the ultrastructure of the mammary epithelium. It provides, in addition to the structure of the specialized junctional complexes in the murine mammary gland, a very beautiful developmental sequence showing changes in ductal and alveolar cells from pregnancy to lactation and the associated changes in the structure of the tight junctions, most beautifully illustrated by freeze fracture images. Pitelka makes the important point that both intermediate junctions and desmosomes are extremely rare in the epithelium of the lactating gland, although they can be readily observed at earlier stages. Consistent with the findings of Linzell and Peaker [5], she also shows that the tight junction in the lactating gland constitutes a permeability barrier which prevents the flux of such electron opaque substances as ruthenium red and horseradish peroxidase across the epithelium.

Since these two landmark studies, there has been relatively little work on this fascinating transition from a highly

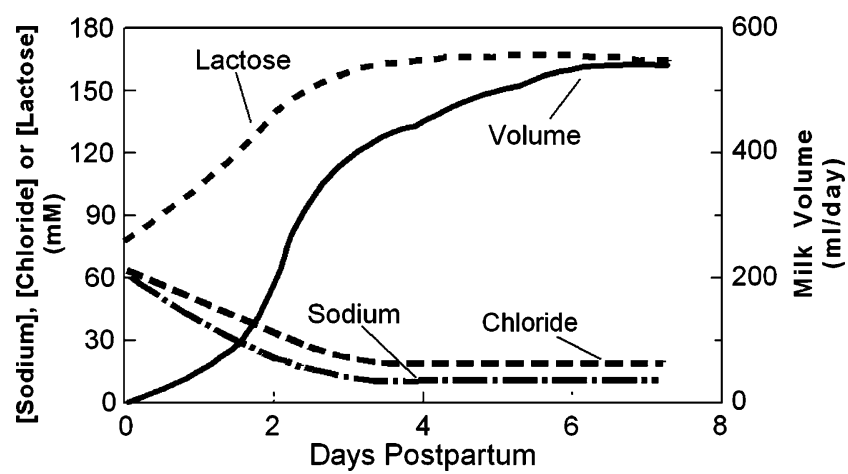

Figure 1 The concentrations of lactose, sodium, and chloride in human milk in relation to milk volume at the onset of lactation. Data replotted from (1). 
permeable epithelium in pregnancy to the tight epithelium of lactation. A study by Berga [7] showed that, similarly to rats and guinea pigs [4], the alveolar epithelium of the lactating mouse gland maintains a potential difference of $-35 \mathrm{mV}$ between the alveolar lumen and the interstitial space, indicating a very tight epithelium indeed. In the same paper Berga used dye transfer techniques to confirm the existence of gap junctions both between mammary epithelial cells and between epithelial cells and myoepithelial cells, as predicted by the localization of gap junctions in the landmark Pitelka paper. Nguyen and colleagues [8] showed that the epithelium of the mouse was permeable to molecules as large as serum albumin in pregnancy, but impermeable even to ${ }^{14} \mathrm{C}$-sucrose in lactation. This change is brought about in vivo by the fall in progesterone that accompanies parturition, and requires both glucocorticoid and either prolactin or placental lactogen. Studies by Fischer and colleagues implicate the Rho pathway in the transition to sealed tight junctions in the mouse mammary gland [9]. Very recently Horseman and colleagues have implicated serotonin in mammary tight junction regulation [10, 11]. However, there is much to be learned about this fascinating transition in the mammary epithelium.

\section{References}

1. Neville MC, Keller RP, Seacat J, Lutes V, Neifert M, Casey CE, et al. Studies in human lactation: milk volumes in lactating women during the onset of lactation and full lactation. Am J Clin Nutr. 1988;48:1375-86.

2. Macy IG, Kelly HJ, Sloan RE. The composition of milks: a compilation of the comparative compositionand properties of human cow and goat; milk colostrum and transitional milk. Washington, D.C: National Academy of Sciences-National Research Council; 1953.

3. Barry JM, Rowland SJ. Variations in the ionic and lactose concentrations of milk. Biochem J. 1953;54:575-8.

4. Linzell JL, Peaker M. Mechanism of milk secretion. Physiol Rev. 1971;51:564-97.

5. Linzell JL, Peaker M. Changes in colostrum composition and in the permeability of the mammary epithelium at about the time of parturition in the goat. J Physiol. 1974;243:129-51.

6. Pitelka DR, Hamamoto ST, Duafala JG, Nemanic MK. Cell contacts in the mouse mammary gland. I. Normal gland in postnatal development and the secretory cycle. J Cell Biol. 1973;56:797-818.

7. Berga SE. Electrical potentials and cell-to-cell dye movement in mouse mammary gland during lactation. Am J Physiol. 1984;247: C20-5.

8. Nguyen DA, Parlow AF, Neville MC. Hormonal regulation of tight junction closure in the mouse mammary epithelium during the transition from pregnancy to lactation. J Endocrinol. 2001; 170:347-56.

9. Fischer A, Stuckas H, Gluth M, Russell TD, Rudolph MC, Beeman NE, et al. Impaired tight junction sealing and precocious involution in mammary glands of PKN1 transgenic mice. J Cell Sci. 2007;120:2272-83.

10. Stull MA, Pai V, Vomachka AJ, Marshall AM, Jacob GA, Horseman ND. Mammary gland homeostasis employs serotonergic regulation of epithelial tight junctions. Proc Natl Acad Sci U S A. 2007;104:16708-13.

11. Pai VP, Horseman ND. Biphasic regulation of mammary epithelial resistance by serotonin through activation of multiple pathways. J Biol Chem. 2008;283:30901-10. 